\title{
Hळ control option for a combined energy and attitude control system
}

\begin{abstract}
A combined energy and attitude control system (CEACS) is a hybrid system that uses flywheels to store energy and provide a simultaneous attitude control in satellites. Previous work appeared in Advances in Space Research (ASR) employing the proportional-derivative (PD) control has proven that CEACS works well and achieves its mission requirement. However, the in-orbit system performance uncertainties present a challenge to the CEACS attitude pointing capability. Thus, this paper complements the previous mentioned work, and focuses on employing the Hळo optimal attitude control solution for the CEACS attitude control enhancement. The mathematical model and numerical treatments for the CEACS Hळ control architecture are presented. Numerical results show that a better attitude pointing accuracy at least up to $0.043^{\circ}$ can be achieved with the $\mathrm{H} \infty$ control method.
\end{abstract}

Keyword: Hळ control; Optimal control; Satellite attitude control; CEACS 